The knowledge, attitude, and practice of consumers towards food safety issues: A review of Taiwan

Dong, Thi Tra My

Department of Business Administration, Lunghwa University of Science and Technology, Taiwan (annie.ju.1990@gmail.com)

Received: 7 January 2015

Available Online: 17 May 2015

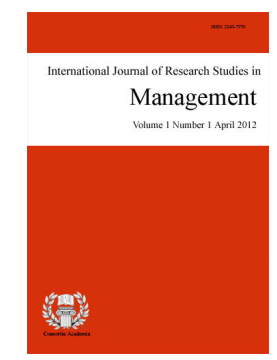

ISSN: 2243-7770 Online ISSN: 2243-7789 OPEN ACCESS

\title{
Abstract
}

Within the last two decades, the widespread food scandals, global fears of food and foodborne outbreaks highlight consumers' concerns and authorities' attention to food safety. Therefore, food safety issue is presently a global health-related concern in community. Many recent food scandals have responded in worries and confusion. Therefore, the study aim of this study is to investigate the consumers' knowledge, attitude, and practice extent towards food safety issues in Taiwan food industry.

Keywords: literary review; food safety; knowledge; attitude; practice 


\section{The knowledge, attitude, and practice of consumers towards food safety issues: A review of Taiwan}

\section{Introduction}

Food safety is a vital issue which relates to the quality of food and producing, allocation as well as consumption avoiding the contaminated and deteriorated food (Prabhakar, Daisuke, and Nalin, 2010). Particularly, it also continues to be the anxieties of the consumer, the food industry together with the regular agency (Brewer \& Rojias, 2007). In other words, Henson and Traill (1993) explain food safety as the inverse of food risk or can be described as the probability of not suffering some hazard from consuming a specific food. In general, food safety is public health precedence. This is due to the fact that millions of people get ill and leading many die each year, as a consequence of consuming unsafe food (WHO, 2009). Currently, there is the spread of more than 200 diseases through food; and beyond, those foodborne illnesses are on the increase worldwide. Food safety, therefore, is the global concern. In the past, each continent has recorded desperate outbreaks of foodborne infections, and continuously, the rate of those diseases is considerably rising in many nations (WHO, 2009). Within a wider context, the problem of food safety not only effects human health but also causes the economic damage of nations.

Annually, Health Canada estimates 2.2 million cases of foodborne illness in Canada, bringing about $\$ 1.3$ billion of social cost annually (Harris, 1997). In United States, foodborne infection affects between 6.5 and 33 million people, with medical costs and productivity losses that have been calculated at around 9.3 to \$12.9 USD billion (Busby, Roberts, Lin, \& MacDonald). In 1996, it is estimated that at least 9,578 inhabitants that children are in the majority suffered from serious Escherichia coli infections related to white radish sprouts in a Japanese epidemic (Caroline \& Nadine, 2005). Additionally, approximately 700,000 people die of water and food safetyrelated reasons in the mere Asia-Pacific region each year. Furthermore, based on the statistics of Vietnam food administration (VFA), food poisoning affects more than 3,187 people in the only first half of 2013. It is obvious that the developing countries and the developed nations all suffer foodborne diseases and the incidence of those infections is increasing (Redmond \& Griffith, 2003). Notwithstanding, food safety problem is stated that the developing lands are more predominant (Mclntyre et al., 2009) or greater impact (WHO, 2007) than industrialized ones.

In the last years of the 20th century, FAO (Food and Agriculture Organization) underscored food safety is as one of the major challenges in accomplishing global food security (1996); then afterwards, FAO $(2002,2008)$ continuously points out that food security is of ever rising to consider global peace as well as stability in the $21 \mathrm{st}$ centuries. The establishment of an effective food control system, therefore, is the key element in the process because main parts of such system are the creation and implementation of a food law. It aims to identify and suggest a policy for the long-term management and control of food safety that meets consumers' confidence and ensures public health. According to guidelines for strengthening National Food Control Systems (FAO/WHO Rome, 2003), there are some aspects that food legislation should include, as follows:

$>\quad$ It must provide a high level of health protection;

$>\quad$ It should include clear definitions to increase consistence and legal security;

$>\quad$ It should be based on high quality, transparent, and independent scientific-advice following risk assessment, risk management and risk communication;

$>\quad$ It should include provision for the use of precaution and the adoption of provisional measures where an unacceptable level of risk to health has been identified and where full risk assessment could be performed; 
The knowledge, attitude, and practice of consumers towards food safety issues: A review of Taiwan

$>$ It should include provisions for the right of consumer to have access to accurate and sufficient information;

$>\quad$ It should provide for tracing of food products and for their recall in case of problems;

$>$ It should include clear provisions indicating that primary responsibility for food safety and quality rests with producers and processors;

$>$ It should include obligation to ensure that only safe and fairly presented food is placed on the market;

$>$ It should also recognize the country's international obligation particularly in relation to trade; and

$>\quad$ It should ensure transparency and the development of food law and access to information.

Similarly, according to World Health Organization (WHO, 2009), in key global food safety concerns, alongside spread of microbiological hazards (including such bacteria as Salmonella or Escherichia coli, e. coli), chemical food contaminants, assessment of new food technologies (such as genetically modified food), and the last one, a strong food system in most countries to ensure a safe global food chain is also underscored. Referring to the performers in food control system, Spencer (2003) indicates food safety controls are progressively concentrating on the food chain as a whole. As evidence of this, FAO has published its own position research on the food chain approach to food safety, and shown that its approach highlights "the responsibility for the supply of safe food is shared along the entire supply chain by all involved with the production, processing, trade and consumption of food".

A variety of protection control systems is in place for the typical food product being provided on the market to customers (Henson, 1997; Caswell, 1997). Spencer (2003) further denotes that national food safety controls and food safety capacity, more commonly, can be observed from a wide range of notions. The framework embraced here is that established by the Inter-American Institute for operation in Agriculture (IICA). Three basic objectives of a food safety control system are described in this framework, including:

$>$ Protection of the human population from hazards in agricultural and food products that pose of threat to human health.

$>$ Improvement of hygienic handling of agricultural products for human consumption.

$>$ Regulation of inputs used in agricultural production, including animal feed, agrochemicals and biological materials.

In order to obsess these objectives, a series of functions need to be taken. Alongside these functions, the key elements of basic capacity issues which underlie the establishment of an effective and efficient system of food safety controls are identified (see Spencer, 2003 for more details).

Another view towards how food is transformed into unsafe, it is said that majority of problems in safe food can be traced through the evidences of how food is produced over the past few decades (Prabhakar et al., 2010). More specific, a large number of food safety issues involves in many stages of how food is produced, processed, marketed along consumed. In other words, according to Australia New Zealand Food Authority (2001) in many different periods when food is manufactured, preserved, delivered, traded as well as consumed implementation, it is effortless for food to turn unsafe. Hence, within many solutions for food safety promotion, Prabhakar et al. (2010) investigate the policy options and actions in the Asia-Pacific region could be widespread classified as two instruments: regulatory and non-regulatory. The former comprises of food safety standards and certifications as the most important attribute. While, institutional and technical capacity constructions (such as, establishments of food safety testing laboratories, cold storage and transportation facilities, food safety reporting and monitoring systems) and better perception generations of food safety among consumers and food producers are represented the latter. 
In conclusion, food safety has an important influence on consumers' health. Besides human health aspect, it significantly effects on the economy of the nations, which demands an amount of money to treat its consequences and improve; as well as on the food industry if consumers lost their beliefs, it is far straightforward to regain their credibility. Ultimately, Prabhakar et al. (2010) echo that "food safety is essential to achieving holistic global food security and is one of the most serious challenges facing mankind in the 21st century" ( $\mathrm{p}$. 216). Neither any nation can ignore food safety problem on its territory, nor is the exception in Taiwan. Additionally, college student is one of the object groups needed to be concerned in this issue. The literature review of food safety both in Taiwan and of college students are presented as follows.

\section{Issues in Taiwan}

Food and Drug Administration (FDA) of Taiwan announces 4963 cases of food-borne illness during 1981-2010. The poisoning situations mainly occur at homes together with at foodservice venues (for instances restaurants, school, food vendors, and many others). The former place is primarily during 1981-1990 whereas the later ones are during 1991-2010 (Sun, Wang, \& Huang, 2012). Subsequently, comparing the two decade of 20 years period from 1991-2010, the average annual number of outbreaks during 2001-2010 is considerably higher than during 1991-2000 (see tables 1 and 2).

\section{Table 1}

Outbreaks, cases, and incidence of foodborne diseases in Taiwan during 1991-2010

\begin{tabular}{ccc}
\hline Year & Outbreaks & Cases \\
\hline 1991 & 93 & 2378 \\
1992 & 88 & 3084 \\
1993 & 77 & 2150 \\
1994 & 102 & 4276 \\
1995 & 123 & 4950 \\
1996 & 178 & 4043 \\
1997 & 234 & 7235 \\
1998 & 180 & 3951 \\
1999 & 150 & 3112 \\
2000 & 208 & 3759 \\
2001 & 178 & 2955 \\
2002 & 262 & 5566 \\
2003 & 251 & 5283 \\
2004 & 274 & 3992 \\
2005 & 247 & 3530 \\
2006 & 265 & 4401 \\
2007 & 248 & 3231 \\
2008 & 272 & 2924 \\
2009 & 351 & 4642 \\
2010 & 503 & 6880 \\
\hline TOTAL & 4284 & 82342 \\
\hline
\end{tabular}

During the previous decades, the majority of food safety incidents have happened in Taiwan. Li, Yu, Lai, and Ko (2012) review and meticulously examine these diseases systematically in order to implement two objectives of providing consumers with roots to realize the dangerous elements as well as averting them to occur as similar conditions in the future. Based on their researching, these incidents are listed as follows: U.S. Beef, grouper fish with malachite green, Chinese hairy crab, poisonous trout, U.S. wheat with malathion, pork with ractopamine, poisonous milk (melamine), fried oil with arsenic, plasticizer.

Throughout 2013, it shocks consumers in Taiwan because of food safety scandals' a string. As evidences of this, the review of the news relating to food safety was broadcasted on both the international and domestic press. Taking some examples as United Daily News (one of the three largest newspapers in Taiwan) (on December 31 st), it posted "food scare" was rated as the top one news of its country. Regarding to FTV (Formosa TV, a 
The knowledge, attitude, and practice of consumers towards food safety issues: A review of Taiwan

reputed television station of Taiwan), the 2013 Taiwan food scandal indicated to incidents of food safety, consisting of "cooking oil, health pills, alcoholic beverages, milk and rice" (on November 28th). According British Broadcasting Corporation, BBC news (on November 19th), a short video named "Taiwan food scares hit shoppers' confidence" given the content about a chain of food safety scandals in this land.

Table 2

Locations of food mishandling in FBDO in Taiwan, 1991-2010

\begin{tabular}{ccccccc}
\hline \multirow{2}{*}{ Location } & \multicolumn{2}{c}{$1991-2010$} & \multicolumn{2}{c}{$1991-2000$} & \multicolumn{2}{c}{$2001-2010$} \\
\cline { 2 - 6 } & Outbreaks & Cases & Outbreaks & Cases & Outbreaks & Cases \\
\hline Home & $28(13)$ & $181(4)$ & $18(12)$ & $154(4)$ & $39(14)$ & $207(5)$ \\
Food service & $84(39)$ & $914(22)$ & $42(29)$ & $800(21)$ & $125(44)$ & $1027(24)$ \\
School & $43(20)$ & $1956(48)$ & $27(19)$ & $1707(44)$ & $59(21)$ & $2206(51)$ \\
Office & $20(9)$ & $418(10)$ & $19(13)$ & $507(13)$ & $21(7)$ & $329(8)$ \\
Hospital & $2(1)$ & $21(<1)$ & $2(1)$ & $29(1)$ & $1(<1)$ & $12(<1)$ \\
Transportation & $2(1)$ & $33(1)$ & $2(1)$ & $35(1)$ & $2(1)$ & $32(1)$ \\
Army & $4(2)$ & $80(2)$ & $3(2)$ & $80(2)$ & $4(1)$ & $79(2)$ \\
Outdoors & $1(1)$ & $32(1)$ & $1(1)$ & $38(1)$ & $1(<1)$ & $26(1)$ \\
Snack booth & $4(2)$ & $17(<1)$ & $2(1)$ & $11(<1)$ & $7(2)$ & $24(1)$ \\
Catering & $23(10)$ & $377(9)$ & $25(18)$ & $484(12)$ & $18(6)$ & $269(6)$ \\
Other & $6(3)$ & $104(3)$ & $4(3)$ & $63(2)$ & $8(3)$ & $141(3)$ \\
\hline
\end{tabular}

In addition, the Central News Agency (CNA), the national news organization of Taiwan, it stated from the Ministry of Health and Welfare that oil was not made from olives but labeled and sold as olive oil together those containing banned chemical must be destroyed (on October 27th). Moreover, CNA also reported that industrial starch prohibited in food but found in tapioca balls that were used in pearl milk tea or beverage of bubble tea (on May 25th). Therefore, it calls attention that "a series of food safety scandals in Taiwan has hurt consumer confidence, and now there are worries they could dent the island's economic growth and damage tourism".

\section{Food safety of college students}

As far as the concerns of food safety of college students, it is given that "college students are one of the most at-risk population groups" due to their unsafe behaviors in food consuming. Furthermore, a study which is implemented at Ohio State University (U.S) infers that undergraduate students are at a higher risk of foodborne illnesses than the general population as they are engaging in the behaviors of both unsafe food handle and consumption (Morrone et al., 2003). In order to entirely comprehend the behaviors of this object group engaging in food safety practice, a large number of research papers have been conducted.

Janoff (1999) indicates that college-aged people have specific desires and demands as consumers because they often experience their self-determination for the first time far from home. Similarly, some noted that college students with a pattern of food consumption are concern because they have tendencies to skip meals (Gottschalk, Macaulay, Sawyer, \& Miles, 1977), eat diets excessively low in energy (Miller, Coffman, \& Linke, 1980), and stay away from particular types of nutritious food (Stasch, Johnson, \& Spangler, 1970). Additionally, many college students prepare meals serving themselves and others (roommates, classmates, and many others) for the first time in life and food safety, therefore, becomes a special anxiety in university or college campuses (Morrone $\&$ Rathbun, 2003). Healthy eating is also reported to be among the issues of current Taiwan university students (Lin, Pan, \& Ching, 2015). Moreover, under the pressure of obtaining a college education, eating whatever is convenient decided by many students.

The previous papers on adults claim that there is an increasing tendency towards food safety knowledge with age and practice in which younger respondents point out additional food safety education plays the greatest necessity and males have lower food safety knowledge scores than females (Byrd-Bredhenner, Schaffner, Bruhn, Blalock, \& Wheatley, 2006; Rimal, Fletcher, McWatters, Mirsa, \& Deodhar, 2001; Sanlier, 2009). Besides food safety education for young adults, Rimal et al. (2001) demonstrate that it is a correlation between food safety 
perceptions and food consumptions of consumers.

Ultimately, the most valuable asset of people is health, college students will become the group of potential consumers in the future, hence their health need to be taken care of thoroughly. College students would certainly be a downright crucial resource of any country. More importantly, it is their future roles for a next healthy generation. With all above respects, it is made the motivation to conduct this study focusing on the subject of college students.

\section{The KAP model}

KAP is the abbreviations of Knowledge, Attitude, and Practice wherein knowledge is a set of understandings; attitude is a way of being, a position; and practice or behavior is the observable actions of an individual in response to a stimulus (Sybille, 2011). Regarding to Wood and Tsu (2008) points of view, a KAP survey is a demonstrative study of a particular population to gather information on what is known (K), believed (A) and done $(\mathrm{P})$ in relation to a specific topic. Similarly, KAP stands for Knowledge, Attitude and Practice used to explore human behavior concerning a topic of "what the respondents know about it $(\mathrm{K})$, how the respondents feel about it (A), what the respondents do about it (P)".

Performing this work, KAP surveys were designed to furnish for programs purposes around the world with the information of knowledge, attitude and practice of households (Cleland, 1973; Ratcliffe 1976). In the 1960s and 1970s, KAP questionnaires began to be used for comprehending family planning standpoints in Africa (Schopper, Doussantousse, \& Orav, 1993). KAP surveys build their role as one of the procedures in health behavior and currently, their usages are growing in popularity to obtain information about health-seeking practices (Hausmann-Muela, Muela, \& Nyamongo, 2003; Manderson \& Aaby, 1992). In addition, Sybille (2011) mentioned the following: KAP model can be used in

$>\quad$ Measure the extent of a known situation, to confirm or disprove a hypothesis, provide new tangents of a situation's reality;

$>$ Enhance the knowledge, attitude and practices around specific themes, to identify what is known and done about various subject relating to health;

$>$ Establish the baseline (reference value) for use in future assessments and will help measure the effectiveness of the activities of health education in changing health behaviors;

$>\quad$ Suggest an intervention strategy in light of specific local circumstances and the cultural factors that influence them, to plan activities better suited to the respective population involved.

In the same way, Ellen (2009) reviews three different purposes of KAP studies. The first one is to evaluate KAP with regard to a notion; second is to explore a problem and prepare interference plans as well; lastly the KAP surveys can be considered as a calculated tool (example i.e., see more at Ellen, 2009).

On the other hand, the KAP still maintains some limitations. It is not easy to observe exactly new problems or deepens the comprehensives without including open questions (this type of question remains very few in some cases). Furthermore, knowledge is considered to be beneficial; however, it does not automatically mean that these behaviors will follow. In other words, perhaps there are considered as the gaps between what is known or said and what is done (Sybille, 2011). It is thus concluded that KAP survey is possible not really a specific methodology but more of a theoretical frame for examining human behavior (Ellen, 2009).

Referring to the relationships of the knowledge, attitude and practice in general, Dai, Chen, Yuan, and Yen (2012) indicate that traditional thoughts in the field of education is attitude of learners is directly affected by knowledge and simultaneously, attitude is transformed into practice or behavior. Furthermore, a recent paper by Dong and Ching (2015) also noted the usefulness of such model in assuming relationships among cause and 
The knowledge, attitude, and practice of consumers towards food safety issues: A review of Taiwan

effects. Regarding to Xie (2003), in her research, it explores if students have a greater extent of knowledge, their attitudes are moderately more positive. Furthermore, some relevant studies found that knowledge will straight influence attitude as well as practice, and that attitude will directly impact on practice/ behavior or intentions, except for the case that the level of affect, which knowledge impacts practice through attitude is better than that of knowledge impacts directly on practice (Dai et al., 2012). Lastly, Sybille (2011) points out that practice is more observable than attitude, and it interestingly records that "numerous studies have often shown a low or sometimes no connection between attitude and practice".

\subsection{Knowledge}

Ibrahim (1995) defines knowledge is "the capacity to acquire, retain and use information; a mixture of comprehension, experience, discernment and skill". According to Brucks (1986), the knowledge is "a complicated construction characterized by the structure and the content of the information stored in the memory". Whilst the structure refers to the way the knowledge is represented and celebrated in memory, the content states to the information related to an object which is stored. In this study, this first dimension, Knowledge, provides three various factors, in turn of general knowledge, information source and responsibility awareness.

\subsection{Attitude}

Attitude is discussed as a critical psychological section because it has been founded to influence and forecast many behaviors (Kraus, 1995) together with leading to purchase behavior, consequently (Ajzen, 1991). Moreover, attitudes are also a function of behavioral beliefs; it means if a personal trusts the performance of a particular behavior will lead to a positive result, then this individual will develop a favorable attitude towards such behavior (Ajzen \& Fishbein, 1980). In other words, it so indicate that the more favorable the attitude, the greater the intention to perform the behavior will be. With regards to the second dimension, Attitude, attitude towards organic food, willingness-to-pay and consumer confidence shall be offered respectively.

\subsection{Practice}

With regards to Practice describing, a quote from Ibrahim's study (1995) that "by practice we mean the application of rules and knowledge that leads to action". The third dimension as well as the last dimension in this study, Practice, furnishes consumer behaviors, which engage in three factors, consisting of eating frequency, dining-units selection, and label information. Demands of label information of products are likely to have a considerable effect on the need patterns along with the dynamics of marketplaces for food quality. As information about products quality and usage for features improvement, producing will be competitive for market shares from sales to attribute-conscious, label-using consumers. Items and industrial sectors with less desirable quality information may reformulate or upgrade processes to avoid undesirable comparisons with other products. As labeling remedies to information problems in marketplaces for food item quality are depended upon more heavily, it is critical to develop the ex-post attempt to assess what effect this informational labeling is holding.

Acknowledgement: This paper is part of a thesis written for the partial fulfillment of a MBA degree in Lunghwa University of Science and Technology. 


\section{References}

Ajzen, I. (1991). The theory of planned behaviour. Organizational Behavior and Human Decision Processes, 50, 179-211. http://dx.doi.org/10.1016/0749-5978(91)90020-T

Ajzen, I., \& Fishbein, M. (1980). Understanding Attitudes and Predicting Social Behavior. New Jersey: Prentice Hall, Englewoods-Cliffs.

Australia New Zealand Food Authority. (2001). Safe food Australia: A guide to the food safety standards. Retrieved from http://www.foodstandards.gov.au/publications

Brewer, M. S., \& Rojas, M. (2007). Consumer attitudes toward issues in food safety. Journal of Food Safety, 28, 1-22. http://dx.doi.org/10.1111/j.1745-4565.2007.00091.x

Brucks, M. (1985). The effects of product class knowledge on information search behavior. Journal of Consumer Research, 12(1), 1-15. http://dx.doi.org/10.1086/209031

Busby, J. C., Roberts, T., Lin, C. T., \& MacDonald, J. M. (1996). Bacterial food borne diseases: Medical costs and productivity losses. USA: Food and Consumer Economics Division, Economic Research Service, US Department of Agriculture.

Byrd-Bredbenner, C., Maurer, J., Wheatley, V., Schaffner, D., Bruhn, C., \& Blalock, L. (2007). Food safety self-reported behaviors and cognitions of young adults: Results of a national study. Journal of Food Protection, 70(8), 1917-1926.

Caroline, S. D., \& Nadine, R. (2005). Global and local: Food safety around the world. Washington, DC: Center for science in the public interest.

Caswell, J.A. (1997). Uses of food labelling regulations. Paris, France: OECD.

Cleland, J. (1973). A critique of KAP studies and some suggestions for their improvement. Studies in Family Planning, 4(2), 42-47. http://dx.doi.org/10.2307/1964829

Dai, C. Y., Chen, W. F., Yuan, Y. H., \& Yen, C. H. (2012). A study on modification of knowledge, attitude and practice on vocational high school electronics courses integrated with nanotechnology concept. International Journal of Thermal \& Environmental Engineering, 4(1), 73-79.

Dong, T. T. M., \& Ching, G. S. (2015). A case study on the food safety issues of college students in Taiwan. International Journal of Research Studies in Management, 4(1), 37-58. http://dx.doi.org/10.5861/ijrsm.2015.973

Ellen, V. (2009). Department of Animal Health, Institute of Tropical Medicine, Antwerp, Belgium. Concepts and challenges in the use of Knowledge-Attitude-Practice surveys: Literature review. Retrieved from http://www.snndz.net/resources/literature-reviews/full-reviews

Food and Agriculture Organization (FAO). (1996). Rome Declaration on World Food Security. Retrieved from http://www.fao.org/docrep/003/w3613e/w3613e00.htm

Food and Agriculture Organization (FAO). (2002, 2008). Conflict and food security. Retrieved from http://www.fao.org/worldfoodsummit/msd/y6808e.htm

Food and Agriculture Organization (FAO)/ World Health Organization (WHO). (2003). Codex Alimentarius, Basic Text on Food Hygiene (3rd ed.). Retrieved from http://www.fao.org/docrep/006/y5307e/y5307e00.htm

Gottschalk, P. L., Macaulay, C. M., Sawyer, J. M., \& Miles, J. E. (1977). Nutrient intakes of university students living in residence. Journal Canada Diet Association, 38, 46-51.

Harris, L. (1997). Hamburger hell: Better risk communication for better health. In D. A. Powell \& W. Leiss (Eds.), Mad cows and mothers milk: the perils of poor risk communication (pp. 77-98). McGill-Queen's University Press.

Hausmann-Muela, S., Muela R. J., \& Nyamongo, I. (2003). Health-seeking behavior and the health system's response. DCPP Working Paper. Retrieved from http://www.dcp2.org/file/29/wp14.pdf 
Henson, S., \& Traill, B. (1993). Consumer perceptions of food safety and their impact on food choice. In G. G. Birch \& G. Campbell-Platt (Eds.), Food safety - the challenge ahead (pp. 39-55). Andover: Intercept.

Ibrahim, G. B. (1995). Knowledge, attitude and practice- the three pillars of excellence and wisdom: A place in the medical profession. Eastern Mediterranean Health Journal, 1(1), 8-16.

Janoff, B. (1999). Targeting all ages. Prog Groc, 37-46.

Kraus, S. J. (1995). Attitudes and the prediction of behavior: A meta-analysis of the empirical literature. Personality and Social Psychology Bulletin, 21, 58-75. http://dx.doi.org/10.1177/0146167295211007

Li, J. H., Yu, W. J., Lai, Y. H., \& Ko, Y. C. (2012). Major food safety episodes in Taiwan: Implications for the necessity of international collaboration on safety assessment and management. Kaohsiung Journal of Medical Sciences, 28, S10-S16. http://dx.doi.org/10.1016/j.kjms.2012.05.004

Lin, M.-C., Pan, C.-T., \& Ching, G. S. (2015). Common problems and coping solutions of university students in Taiwan. International Journal of Research Studies in Education, 4(1), 3-16. http://dx.doi.org/10.5861/ijrse.2014.717

Manderson, L., \& Aaby, P. (1992). An epidemic in the field? Rapid assessment procedures and health research. Social Science \& Medicine, 35(7), 839-850. http://dx.doi.org/10.1016/0277-9536(92)90098-B

McIntyre, B. D., Herren, H. R., Wakhungu, J., \& Watson, R.T. (2009). Agriculture at a crossroads: A global report. Washington, DC: IAASTD.

Miller, T. M., Coffman, J. G., \& Linke, R. A. (1980). Survey on body image, weight, and diet of college students. Journal of American Dietetic Association, 77(5), 561-566.

Morrone, M., \& Rathbun, A. (2003). Health education and food safety behavior in the university setting. Journal of Environmental and Health, 65(7), 9-15.

Prabhakar, S. V. R. K., Sano, D., \& Srivastava, N. (2010). Food safety in the Asia-Pacific region: Current status, policy perspectives and a way forward. In Sustainable consumption and production in the Asia-Pacific Region: Effective responses in a resource constrained world, institute for global environmental strategies, white paper III (pp. 215-238). Hayama, Japan: Institute for Global Environmental Strategies.

Ratcliffe, J. W. (1976). Analyst biases in KAP surveys: A cross-cultural comparison. Studies in Family Planning, 7(11), 322-330. http://dx.doi.org/10.2307/1965827

Redmond, E. C., \& Griffith, C. J. (2003). Consumer food handling in the home: A review of food safety studies. Journal of Food Protection, 66(1), 130-161.

Rimal, A., Fletcher, S. M., McWatters, K. H., Misra, S. K., \& Deodhar, S. (2001). Perception of food safety changes in food consumption habits: A consumer analysis. International Journal of Consumer Studies, 25(1), 43-52. http://dx.doi.org/10.1111/j.1470-6431.2001.00162.x

Sanlier, N. (2009). The knowledge and practice of food safety by young and adult consumers. Food Control, 20(6), 538-42. http://dx.doi.org/10.1016/j.foodcont.2008.08.006

Schopper, D., Doussantousse, S., \& Orav, J. (1993). Sexual behaviors relevant to HIV transmission in a rural African population: How much can a KAP survey tell us? Social Science \& Medicine, 37(3), 401-412. http://dx.doi.org/10.1016/0277-9536(93)90270-E

Spencer, H. (2003). The economics of food safety in developing countries ESA working paper No.03-19. Retrieved from http://www.fao.org/es/esa

Stasch, A. R., Johnson, M. M., \& Spangler, G. J. (1970). Food practices and preferences of some college students. Journal of American Dietetic Association, 57(6), 523-527.

Sun, Y. M., Wang, S. T., \& Huang, K. W. (2011). Hygiene knowledge and practices of night market food vendors in Tainan City, Taiwan. Food Control, 23, 159-164. http://dx.doi.org/10.1016/j.foodcont.2011.07.003

Sybille, G. (2011). Data collection, quantitative methods: The KAP survey model. Retrieved from http://www.medecinsdumonde.org 
Wood, S., \& Tsu, V. (2008). Advocacy, communication and social mobilization for TB control: A guide to developing knowledge, attitude and practice surveys. WHO Library Cataloguing-in-Publication Data. Retrieved from http://www.stoptb.org/resource_center/assets/documents/ACSM_KAP\%20GUIDE.pdf

World Health Organization (WHO). (2009). Retrieve from http://www.who.int/features/factfiles/food_safety/en/

Xie, P. S. (2003). A case study on knowledge, attitude, and behavioral intention related to green consumption and related factors for high school students on one school in Taipei County. Unpublished Doctoral dissertation, National Taiwan Normal University, Taipei Taiwan. 